\title{
Psychometric Properties of the Chinese Irrational Procrastination Scale: Factor Structure and Measurement Invariance Across Gender
}

\author{
Amy Shaw ${ }^{1 *}$ and Jennifer J. Zhang ${ }^{2}$ \\ 'Department of Psychology, Faculty of Social Sciences, University of Macau, Taipa, Macau, China, ${ }^{2}$ Department of \\ Psychology, University of Houston, Houston, TX, United States
}

The present paper reports on the preliminary validation of a Chinese version of Steel's Irrational Procrastination Scale (IPS). To this end, the nine items of the IPS were translated

OPEN ACCESS

Edited by:

Paola Gremigni,

University of Bologna, Italy

Reviewed by:

Frode Svartdal,

Arctic University of Norway, Norway

Omid Saed,

Zanjan University of Medical

Sciences, Iran

${ }^{*}$ Correspondence:

Amy Shaw

amyshaw@um.edu.mo

Specialty section: This article was submitted to Quantitative Psychology and

Measurement,

a section of the journal

Frontiers in Psychology

Received: 31 August 2021 Accepted: 24 September 2021 Published: 18 October 2021

Citation:

Shaw A and Zhang JJ (2021)

Psychometric Properties of the Chinese Irrational Procrastination

Scale: Factor Structure and Measurement Invariance Across

Gender.

Front. Psychol. 12:768581. doi: 10.3389/fpsyg.2021.768581 into Chinese and data were collected from a sample of 2,361 mainland Chinese college students. Confirmatory factor analysis (CFA) was used to examine the dimensional structure of the IPS, and multigroup CFA (MG CFA) was carried out to evaluate the measurement invariance across gender. Results revealed that the Chinese IPS had adequate internal consistency reliability, adhered to the one-factor structure, and exhibited strong or scalar invariance across the two gender subgroups, thereby providing support for the internal construct validity of the scale. Additionally, the IPS scores were found to be strongly and negatively related to the Conscientiousness personality trait while showing weak correlations with the other traits, which provided some support for the convergent and divergent validity of the Chinese IPS. Study limitations and future research directions (e.g., expanding the empirical evidence for the scale's criterion-related validity) are discussed.

Keywords: procrastination, irrational procrastination scale, validation study, confirmatory factor analysis, multigroup confirmatory factor analysis, measurement invariance, gender differences, Chinese college students

\section{INTRODUCTION}

Procrastination, the voluntary delay of action despite knowing to become worse off or disadvantageous due to the delay (Steel, 2007, 2010), is viewed as an irrational behavior pattern often associated with negative outcomes such as lower task performance, decreased well-being, increased physical and mental suffering, and unnecessary feelings such as worry, discomfort, guilt, and stress (Tice and Baumeister, 1997; Steel, 2007, 2010; Klingsieck, 2013; Steel and Ferrari, 2013). As a prevalent issue among both the general public and student populations, procrastination has been frequently examined in epidemiological research via self-report measures. Such studies estimated that at least $20 \%$ of the general adult population experiences difficulties related to procrastination (Harriott and Ferrari, 1996) and 50-95\% of the student population engages in procrastinatory behaviors on a daily basis (Day et al., 2000; Ellis and Knaus, 2002; Schouwenburg et al., 2004; Steel, 2007). According to Steel and Ferrari (2013), procrastinators 
are often aware of their own tendency to procrastinate while recognizing procrastination as negative and are also motivated to overcome or reduce it (Steel, 2007).

Given the prevalence and harmful consequences of procrastination, there has been a strong motive to develop and validate psychometrically sound measures for procrastination. Among a multitude of procrastination scales in the literature (see Steel, 2010, for an overview), the Irrational Procrastination Scale (IPS; Steel, 2010, 2002, unpublished) was developed to focus on measuring one single unitary construct - the irrational or dysfunctional delay of intended behavior in the implemental phase (Steel, 2002, unpublished; Andreou, 2007) which was regarded as the most essential attribute of procrastination (Steel, 2007). The IPS contains nine items in total [e.g., "I delay tasks beyond what is reasonable" (Item 7)] all of which are intended to capture the construct of irrational procrastination. Due to its relatively short length, simple unidimensional structure, convenience to administer and score, and adequate psychometric properties (Steel, 2010; Steel and Ferrari, 2013), the IPS has not only become a commonly used and well-established scale for measuring procrastination in English-speaking countries but also attracted considerable attention from the international research community. Several recent adaptation and validation efforts have been made to investigate the psychometric properties of the IPS to support its use in other languages than English [e.g., Indonesian (Prayitno et al., 2013), French (Rebetez et al., 2014), Swedish (Rozental et al., 2014), Polish (Stępień and Topolewska, 2014), Norwegian (Svartdal, 2017), Spanish (Guilera et al., 2018), Russian (Klepikova and Kormacheva, 2019), and Korean (Kim et al., 2020)], but to our knowledge, no validation has been carried out in the Chinese context. Hence, the aim of the current study is to investigate the psychometric properties of the Chinese version of the IPS to provide support for its use in the Chinese settings which in turn would be helpful in facilitating procrastination research and prevention practices in China. Specifically, the internal consistency reliability and factor structure of the scale followed by its measurement invariance across gender as well as the relations to external variables are examined.

\section{MATERIALS AND METHODS}

\section{Participants and Procedure}

This study was part of a larger project for investigating affect and performance. The current sample is comprised of $N=2,361$ mainland Chinese college students who took part in the study for extra credit. Participation was voluntary, anonymous, and confidential. After providing their written informed consent, participants completed a background information sheet that collected data concerning age and gender in addition to the translated and adapted Chinese version of the IPS and a personality measure, both of which will be elaborated upon in the following sections. Questionnaires were completed during class time and then collected on the spot. There were no missing data so that all participants were included in the final analysis sample $(N=2,361)$. Their ages ranged from 18 to
22 years with an average of $19.89(S D=0.56)$. Among these participants, $N=1,294$ (54.8\%) were male.

\section{The IPS-China Form}

To construct the Chinese version of the nine-item IPS (Steel, 2010, 2002, unpublished), the original English version of the IPS was first translated in to simplified Chinese by two independent bilingual translators whose mother tongue was Chinese (forward translation). The translators then discussed and resolved their discrepancies in the initial translation. Afterward, the interim Chinese IPS was retroverted into English by a native English speaker with excellent mastery of Chinese but without knowledge of the original English version (back translation). The back-translated English version was then compared to the original version to ensure that both versions shared the psychological meaning. Finally, all translated versions were discussed for clarification and consolidated in an expert review session, during which a few minor changes were made to the interim Chinese IPS. The items of the adapted Chinese IPS are presented in Table 1. We use the term "adapted" because the translation process emphasized the retainment of the original intent and essential meaning of the scale (Hambleton et al., 2005).

As displayed in Table 1, following the format of the English version, the Chinese IPS contains nine items in total three of which are reversely scored (Items 2, 6, and 9). The participants also rated the IPS on a five-point Likert scale ( 1 = Very seldom/ Not true of me; $5=$ Very often true/True of me). In scoring, all items were coded such that higher numbered responses referred to "more" of the trait and the total score was computed by adding all responses to the nine items. Therefore, higher scores on the scale indicated greater levels of procrastination with a possible total score range of 9-45.

TABLE 1 | Irrational procrastination scale (IPS) items in English and Chinese.

\begin{tabular}{|c|c|c|}
\hline Item & English & Chinese (Simplified) \\
\hline IPS1 & $\begin{array}{l}\text { I put things off so long that my } \\
\text { well-being or efficiency } \\
\text { unnecessarily suffers }\end{array}$ & $\begin{array}{l}\text { 我把事情拖得太久, 以至于我的 } \\
\text { 幸福感或效率受到了不必要的 } \\
\text { 负面影响 }\end{array}$ \\
\hline IPS2 (R) & $\begin{array}{l}\text { If there is something I should } \\
\text { do, I get to it before attending } \\
\text { to lesser tasks }\end{array}$ & $\begin{array}{l}\text { 如果有我该做的事情, 我会先 } \\
\text { 去做这件事, 然后再去处理其 } \\
\text { 它次要的任务 }\end{array}$ \\
\hline IPS3 & $\begin{array}{l}\text { My life would be better if I did } \\
\text { some activities or tasks earlier }\end{array}$ & $\begin{array}{l}\text { 如果我早点儿开始做某些活动 } \\
\text { 或任务的话, 我的生活会更好 }\end{array}$ \\
\hline IPS4 & $\begin{array}{l}\text { When I should be doing one } \\
\text { thing, I will do another }\end{array}$ & $\begin{array}{l}\text { 当我应该做某件事情时, 我反 } \\
\text { 而会去做另一件事 }\end{array}$ \\
\hline IPS5 & $\begin{array}{l}\text { At the end of the day, I know } \\
\text { I could have spent the time } \\
\text { better }\end{array}$ & $\begin{array}{l}\text { 回顾当天, 我知道我本可以更 } \\
\text { 好地使用我的时间 }\end{array}$ \\
\hline IPS6 (R) & I spend my time wisely & 我明智地利用我的时间 \\
\hline IPS7 & $\begin{array}{l}\text { I delay tasks beyond what is } \\
\text { reasonable }\end{array}$ & $\begin{array}{l}\text { 我拖延任务的时间超出了合理 } \\
\text { 范围 }\end{array}$ \\
\hline IPS8 & I procrastinate & 我拖延 \\
\hline IPS9 (R) & $\begin{array}{l}\text { I do everything when I believe } \\
\text { it needs to be done }\end{array}$ & $\begin{array}{l}\text { 只要我认为某件事情需要完成, } \\
\text { 我就会去做它 }\end{array}$ \\
\hline
\end{tabular}

Items designated with an $(R)$ are reverse scored. 


\section{The Personality Measure}

To provide criterion-related validity evidence for the Chinese IPS adapted in the current study, we examined its relations to the Big-five personality traits (Costa and McCrae, 1992) which have been demonstrated to be relevant to procrastination in the literature. Specifically, two meta-analytic studies (Van Eerde, 2003; Steel, 2007) both found that procrastination strongly related to Conscientiousness, while exhibiting low or null relationships with the other traits. Validation studies for the IPS in other countries also revealed large and negative correlations between the IPS scores and Conscientiousness (Rebetez et al., 2014; Guilera et al., 2018). In this study, the Big-five personality traits were measured via the 50-item International Personality Item Pool scale (IPIP; Goldberg et al., 2006) which has been validated in the Chinese setting (Zheng et al., 2008). The IPIP items were administered with a five-point Likert scale $(1=$ Very inaccurate description of me; $5=$ Very accurate description of me). All the trait subscales (with 10 items in each) had satisfactory estimated reliabilities (Cronbach's alpha coefficients ranged from 0.81 to 0.91 ).

\section{ANALYSES AND RESULTS}

\section{Descriptive Statistics}

All planned analyses in the study were based on raw scores in $\mathrm{R}$ version 3.4.4 ( $\mathrm{R}$ Core Team, 2018). The observed IPS total scores for this sample ranged between 9 and 45 with an average of 31.47 ( $S D=5.65, N=2,361)$, suggesting a slightly-greater-thanaverage level of irrational procrastination which accorded well with the general anticipation that college students tended to procrastinate more (Day et al., 2000; Steel, 2007). The skewness value was $S=-0.29$, and the kurtosis value was $K=0.17$ for the total score, both of which were well within the range of -1.00 to 1.00 to consider the score distribution as not deviating from normality (Tabachnick and Fidell, 2013). The distribution statistics suggested that the scale was sufficient in capturing different levels of irrational procrastination among college students and was not limited by any noticeable floor or ceiling effect. Not violating the normality assumption is also important to parameter estimation in the ensuing factor analysis (Kline, 2016).

\section{Reliability}

Comparable to that of the original English version $(\alpha=0.91$; Steel, 2010), the internal consistency reliability of the Chinese IPS (Cronbach's $\alpha=0.91$; McDonald's $\omega=0.92$ ) was excellent per the rule of thumb (Nunnally and Bernstein, 1994). As presented in Table 2, corrected item-total correlations of the nine items on the scale ranged from 0.55 to 0.75 and were all statistically significant at the 0.001 level, suggesting that all items functioned satisfactorily in terms of item discrimination (all correlations were $>0.50$ and in the expected direction; Nunnally and Bernstein, 1994; Clark and Watson, 1995). The high item-total correlations also indicated that all the nine items contributed well to the overall scale and appeared to be defining a central construct, providing some initial evidence for the unidimensionality of scale.

\section{Factor Structure}

The IPS was originally theorized and developed as a unidimensional scale (Steel, 2010, 2002, unpublished), and subsequent empirical examinations of different language versions of the IPS have largely pointed to a single-factor structure of the scale (e.g., Svartdal et al., 2016; Svartdal, 2017; Kim et al., 2020; see also Prayitno et al., 2013; Rozental et al., 2014). Therefore, we expected the Chinese IPS to be also unidimensional and therefore, conducted a confirmatory factor analysis (CFA) using the lavaan package version 0.6-2 (Rosseel, 2018) in $\mathrm{R}$ as a confirmatory test of the unidimensionality. Accordingly, we fit a single-factor model in which all of the nine items loaded on one factor with the robust weighted least squares mean and variance-adjusted (WLSMV) estimator, given the ordinal categorical nature of the response data (Muthén et al., 1997, unpublished; Finney and DiStefano, 2006). Criteria to determine the overall model fit included the Chi-square statistic $\left(\chi^{2}\right)$ and the following goodness-of-fit indices: the comparative fit index (CFI; Bentler, 1990), the Tucker-Lewis index (TLI; Tucker and Lewis, 1973), the root-mean-square error of approximation (RMSEA; Steiger, 1990), and the standardized root-mean-square residual (SRMR). Because of the large sample size in the current study, it would be inappropriate to use Chi-square significance testing for model fit determination as even a small difference would be found to be statistically significant within large samples (Brown, 2015). We thus primarily relied on the inspection of the goodness-of-fit indices employing the standards recommended in the literature; conventionally, $\mathrm{CFI} \geq 0.95$, TLI $\geq 0.95$, RMSEA $\leq 0.06$, and $\mathrm{SRMR} \leq 0.08$ would indicate a very good fit of the model to the data (Browne and Cudeck, 1993; Hu and Bentler, 1999; Kline, 2016). All the goodness-of-fit indices in this study were excellent $\left[\chi^{2}(27)=260.16, p<0.001, \mathrm{CFI}=0.990, \mathrm{TLI}=0.988, \mathrm{SRMR}=0.048\right.$, and $\mathrm{RMSEA}=0.060]$, demonstrating that the parsimonious single-factor model represented the data satisfactorily. Moreover, as shown in Table 2, all items exhibited good factor loadings on the latent factor (ranging from 0.58 to 0.80 and statistically significant at the 0.001 level), further supporting the adequate discriminating power of the items across the latent range of the construct. Also, there was no modification index suggested for any type of cross-loading, and thus, each item was considered

TABLE 2 | Item-total correlations and factor loadings of the Chinese IPS.

\begin{tabular}{lcc}
\hline Item & $\begin{array}{c}\text { Standardized factor } \\
\text { loading }\end{array}$ & $\begin{array}{c}\text { Item-total correlation } \\
\text { (corrected) }\end{array}$ \\
\hline IPS1 & $0.80^{*}$ & $0.75^{\star}$ \\
IPS2 (R) & $0.68^{\star}$ & $0.63^{*}$ \\
IPS3 & $0.58^{\star}$ & $0.55^{\star}$ \\
IPS4 & $0.76^{\star}$ & $0.72^{\star}$ \\
IPS5 & $0.79^{*}$ & $0.73^{*}$ \\
IPS6 (R) & $0.69^{*}$ & $0.65^{\star}$ \\
IPS7 & $0.65^{\star}$ & $0.61^{*}$ \\
IPS8 & $0.78^{\star}$ & $0.73^{*}$ \\
IPS9 (R) & $0.67^{*}$ & $0.62^{*}$ \\
\hline
\end{tabular}

"denotes $p<0.001$.

Items designated with an $(R)$ are reverse scored. 
as the exclusive indictor of the intended latent variable (i.e., irrational procrastination).

\section{Measurement Invariance Across Gender}

Once the unidimensionality was confirmed, we proceeded to test the one-factor model on male and female students separately to evaluate the measurement equivalence or invariance across gender subgroups of the Chinese IPS. Although no gender difference was observed in the IPS scores in this sample [IPS-TotalMale $=31.48$ vs. IPS-Total-Female $=31.45, t(2359)=0.13, p=0.89$ ], previous research (e.g., Steel and Ferrari, 2013; Beutel et al., 2016; Guilera et al., 2018) has identified gender differences in procrastination with males procrastinating more than females (albeit the effect sizes were small). Conclusions about gender differences (or lack thereof) under study cannot be settled until measurement invariance (a prerequisite for meaningful score comparisons across groups) of the instrument has been established (Millsap and Olivera-Aguilar, 2012; Brown, 2015; Kline, 2016).

A multigroup men vs. women CFA (MG CFA) was thus performed over gender subgroups using standard procedures to test for configural invariance (equal form), metric/weak invariance (equal loadings), and scalar/strong invariance (equal intercepts) in increasingly restrictive steps (Millsap and OliveraAguilar, 2012; Kline, 2016). Strict invariance (equal residual errors) was not tested because it is often considered as overly stringent and unnecessary by methodologists and has rarely been observed in practice (e.g., Cheung and Lau, 2012; Brown, 2015; Van De Schoot et al., 2015). In determining invariance, we placed more emphasis on changes in model fit indices (the CFI, SRMR, and RMSEA values; Cheung and Rensvold, 2002) relative to the Chi-square difference significance tests of the nested models between each successive step, because one would expect the likelihood ratio-based Chi-square tests to be significant (an indication of non-invariance) with a large sample size (Brown, 2015). To determine that measurement invariance holds for the more constrained model in each comparison, $\triangle$ CFI should be less than $0.010, \Delta$ SRMR should be less than 0.01 , and $\triangle$ RMSEA should not exceed 0.015 (Cheung and Rensvold, 2002; Chen, 2007). Table 3 summarizes the MG CFA results. Overall, the fit statistics supported the measurement invariance for the Chinese IPS across gender in metric invariance $(\Delta \mathrm{CFI}=-0.002, \Delta \mathrm{SRMR}=0.003$, and $\Delta \mathrm{RMSEA}=0.001)$ and scalar invariance $(\Delta \mathrm{CFI}=-0.001$,
$\Delta \mathrm{SRMR}=0.003$, and $\triangle \mathrm{RMSEA}=-0.002)$ as the changes in the fit indices did not indicate meaningful decrement in model fit (Cheung and Rensvold, 2002; Chen, 2007). Therefore, we decided that the Chinese IPS assessed irrational procrastination equivalently across gender, which ensured meaningful score comparisons between men and women.

\section{Relations to Personality Traits}

By examining Pearson's correlation coefficients between the IPS scores and external construct-related variables (i.e., the Big-five personality traits), we evaluated the concurrent validity of the Chinese IPS. In line with past works on the personality correlates of the IPS total scores (e.g., Van Eerde, 2003; Steel, 2007; Rebetez et al., 2014; Guilera et al., 2018), procrastination measured by the Chinese IPS was found to be negatively and strongly related to Conscientiousness $(r=-0.61, p<0.001)$ while showing weak relations to the other traits: Extraversion $(r=-0.13, p<0.001)$, Agreeableness $(r=-0.12, p<0.001)$, Emotional Stability $(r=-0.20$, $p<0.001)$, and Openness to Experience $(r=0.11, p<0.001)$. Therefore, the Chinese IPS scores were correlated with the Big-five personality traits in the expected direction and magnitudes according to the standards suggested by Cohen (1988).

\section{DISCUSSION}

The study purpose was to investigate the psychometric properties of the IPS, one of the most widely used procrastination assessments in the current literature, to provide validity evidence for its use in the Chinese context. In line with the aim of the study, we first translated and adapted the original IPS into a Chinese version and then evaluated the internal consistency reliability, factor structure, and gender-based measurement invariance of the scale. Overall, the results suggested promising psychometric properties of the Chinese version of the IPS. In agreement with previous research (e.g., Steel, 2010; Rozental et al., 2014; Svartdal et al., 2016; Svartdal and Steel, 2017; Guilera et al., 2018), we found adequate internal consistency reliability of the nine-item scale within this sample. Regarding the dimensionality, the CFA results confirmed the one-factor structure of the IPS, which fit well with the original idea of the scale (as a unidimensional measure of irrational procrastination) put forward by Steel (2010, 2002, unpublished) as well as conclusions from prior validation studies

TABLE 3 | Measurement invariance across gender through multigroup confirmatory factor analysis (MG CFA).

\begin{tabular}{|c|c|c|c|c|c|c|c|c|}
\hline \multirow[t]{2}{*}{ Models and comparisons } & \multicolumn{8}{|c|}{ Fit statistics } \\
\hline & $\chi^{2}(d f)$ & CFI & SRMR & RMSEA & $\Delta \chi^{2}(\Delta d f)$ & $\Delta \mathrm{CFI}$ & $\Delta$ SRMR & $\triangle$ RMSEA \\
\hline Configural model (Model 1) & $347.92(54)^{*}$ & 0.984 & 0.053 & 0.067 & & & & \\
\hline Metric model (Model 2) & $407.45(62)^{*}$ & 0.982 & 0.056 & 0.068 & & & & \\
\hline Scalar model (Model 3) & $442.91(70)^{\star}$ & 0.981 & 0.059 & 0.066 & & & & \\
\hline $\begin{array}{l}\text { Configural vs. Metric: } \\
\text { Model } 2 \text { - Model } 1\end{array}$ & & & & & $59.53(8)^{*}$ & -0.002 & 0.003 & 0.001 \\
\hline Metric vs. Scalar: Model 3 - Model 2 & & & & & $35.46(8)^{*}$ & -0.001 & 0.003 & -0.002 \\
\hline
\end{tabular}

$\mathrm{CFI}=$ comparative fit index; SRMR = standardized root-mean-square residual; and RMSEA = root-mean-square error of approximation. ${ }^{*}$ denotes $p<0.001$. 
in other languages and countries/regions (e.g., Svartdal et al., 2016; Svartdal, 2017; Kim et al., 2020; Shaw and Zhang, 2021). Furthermore, measurement invariance held across gender, demonstrating that the Chinese IPS was not biased against men or women and that any gender difference in the scale scores would be attributable to the underlying psychological construct itself. As such, the study also provided evidence for the appropriate use of the Chinese IPS as an instrument of measuring gender differences in irrational procrastination. In addition, the observed correlates with the Big-five personality traits were as expected and consistent with the findings reported in recent works (Van Eerde, 2003; Steel, 2007; Rebetez et al., 2014; Guilera et al., 2018), providing some evidence for the scale's convergent and divergent validity.

Several study limitations should be taken into account while reviewing the present findings. First, the Chinese IPS clearly needs further examination and validation, especially with respect to the evaluation of criterion-related validity. Future investigations of its relations with external variables such as other currently available Chinese procrastination instruments [e.g., the Aitken Procrastination Inventory originally developed by Aitken (1982, unpublished) and recently adapted into Chinese by Chen et al. (2008), the Tuckman Procrastination Scale originally developed by Tuckman (1991) and then validated in the Chinese setting by Zhang and Zhang (2007)] would be highly desirable for expanding its convergent validity. Future research may also assess the predictive validity of the Chinese IPS on outcome measures such as subjective well-being measured by the Satisfaction With Life Scale (SWLS; Diener et al., 1985; Chinese version validated by Bai et al., 2011), an outcome variable that has been well-demonstrated to be negatively affected by procrastination (Steel, 2010; Sirois and Tosti, 2012; Rebetez et al., 2014; Beutel et al., 2016; Svartdal, 2017; Guilera et al., 2018). Second, to complement the present study utilizing the classical test theory (CTT) and factor analysis, future research could apply the more modern item response theory (IRT; Embretson and Reise, 2000) techniques for additional item-level diagnostic metrics (e.g., Shaw et al., 2021; see also Shaw et al., 2020 for a recent discussion on applying advanced IRT models in the validation and refinement of measures). Third, because we adopted a college student sample, it is unclear whether the patterns of the present findings may generalize to other populations such as working adults. Given that past works have found the student population to be particularly prone to procrastination (Day et al., 2000; Steel, 2007; Steel and Ferrari, 2013; Hicks and Storey, 2015; Svartdal, 2017), further research with more heterogeneous samples is warranted to try to replicate the current findings. Fourth, even though considerable effort was devoted to the

\section{REFERENCES}

Andreou, C. (2007). Understanding procrastination. J. Theory Soc. Behav. 37, 183-193. doi: 10.1111/j.1468-5914.2007.00331.x

Bai, X., Wu, C., Zheng, R., and Ren, X. (2011). The psychometric evaluation of the satisfaction with life scale using a nationally representative sample of China. J. Happiness Stud. 12, 183-197. doi: 10.1007/s10902-010-9186-x translation and adaption process in order to retain the core meaning of the original scale and to ensure the content quality of the Chinese IPS items, it is likely that linguistic or cultural differences still introduced construct-irrelevant biases to the process which in turn, affected respondents' interpretation of the items. To help clarify such potential issues, future studies may conduct cognitive interviews which presumably could provide direct and valuable insights into how the target construct (i.e., irrational procrastination) might be regarded by participants in their individual response processes (Krosnick, 1999; Hambleton et al., 2005; Shaw et al., 2020).

In sum, as an initial validation study, our paper presented preliminary validity evidence supporting the use of the IPS in the Chinese context. The findings are in accordance with conclusions from studies that corroborated the psychometric soundness of the IPS in other countries (e.g., Svartdal et al., 2016; Svartdal, 2017; Guilera et al., 2018; Kim et al., 2020; Shaw and Zhang, 2021). At present, there has been accumulated evidence globally that suggests the utility of the IPS as a brief and valid scale for assessing procrastination. In response to the growing need of useful and easy-to-administer procrastination scales in an international context, we encourage further investigations of the Chinese IPS to strengthen and expand its validity evidence as well as call for more attempts at adapting and validating the IPS in additional non-English speaking populations. Collectively these validations studies may allow for future cross-cultural comparisons on procrastination with a well-established instrument.

\section{DATA AVAILABILITY STATEMENT}

The original contributions presented in the study are included in the article, further inquiries can be directed to the corresponding author.

\section{AUTHOR CONTRIBUTIONS}

AS and JZ contributed to the conceptualization, data collection, data analysis, and manuscript preparation.

\section{ACKNOWLEDGMENTS}

Support from the SRG Research Program of the University of Macau (Reference Number: SRG2018-00141-FSS) is gratefully acknowledged.

Bentler, P. M. (1990). Fit indexes, Lagrange multipliers, constraint changes and incomplete data in structural models. Multivar. Behav. Res. 25, 163-172. doi: 10.1207/s15327906mbr2502_3

Beutel, M. E., Klein, E. M., Aufenanger, S., Brähler, E., Dreier, M., Müller, K. W., et al. (2016). Procrastination, distress and life satisfaction across the age range-a German representative community study. PLoS One 11:e0148054. doi: 10.1371/journal.pone.0148054 
Brown, T. A. (2015). Confirmatory Factor Analysis for Applied Research. New York, NY: Guilford.

Browne, M. W., and Cudeck, R. (1993). "Alternative ways of assessing model fit," in Testing Structural Equation Models. eds. K. A. Bollen and J. S. Long (Newbury Park, CA: Sage), 136-162.

Chen, F. F. (2007). Sensitivity of goodness of fit indexes to lack of measurement invariance. Struct. Equ. Model. 14, 464-504. doi: 10.1080/10705510701301834

Chen, X., Dai, X., and Dong, Q. (2008). A research of Aitken procrastination inventory applied to Chinese college students. Chinese J. Clin. Psychol. 16, 22-23.

Cheung, G. W., and Lau, R. S. (2012). A direct comparison approach for testing measurement invariance. Organ. Res. Methods 15, 167-198. doi: 10.1177/1094428111421987

Cheung, G. W., and Rensvold, R. B. (2002). Evaluating goodness-of-fit indexes for testing measurement invariance. Struct. Equ. Model. 9, 233-255. doi: 10.1207/S15328007SEM0902_5

Clark, L. A., and Watson, D. B. (1995). Constructing validity: basic issues in objective scale development. Psychol. Assess. 7, 309-319. doi: 10.1037/1040-3590.7.3.309

Cohen, J. (1988). Statistical Power Analysis for the Behavioral Sciences 2nd Edn. Hillsdale, NJ: Lawrence Erlbaum Associates.

Costa, P. T., and McCrae, R. R. (1992). Normal personality assessment in clinical practice: the NEO personality inventory. Psychol. Assess. 4, 5-13. doi: $10.1037 / 1040-3590.4 .1 .5$

Day, V., Mensink, D., and O'Sullivan, M. (2000). Patterns of academic procrastination. J. Coll. Read. Learn. 30, 120-134. doi: 10.1080/10790195.2000.10850090

Diener, E., Emmons, R. A., Larsen, R. J., and Griffin, S. (1985). The satisfaction with life scale. J. Pers. Assess. 49, 71-75. doi: 10.1207/s15327752jpa4901_13

Ellis, A., and Knaus, W. J. (2002). Overcoming Procrastination, Revised Edition. New York, NY: New American Library.

Embretson, S. E., and Reise, S. P. (2000). Item Response Theory for Psychologists. Mahwah, NJ: Lawrence Erlbaum Associates.

Finney, S., and Distefano, C. (2006). "Nonnormal and categorical data in structural equation modeling," in Structural Equation Modeling: A Second Course. eds. G. Hancock and R. Mueller (Greenwich, CT: Information Age Publishing)

Goldberg, L. R., Johnson, J. A., Eber, H. W., Hogan, R., Ashton, M. C., Cloninger, C. R., et al. (2006). The international personality item pool and the future of public-domain personality assessment. J. Res. Pers. 40, 84-96. doi: 10.1016/j.jrp.2005.08.007

Guilera, G., Barrios, M., Penelo, E., Morin, C., Steel, P., and Gómez-Benito, J. (2018). Validation of the Spanish version of the irrational procrastination scale (IPS). PLoS One 13:e0190806. doi: 10.1371/journal.pone.0190806

Hambleton, R. K., Merenda, P. F., and Spielberger, C. D. (eds.) (2005). Adapting Educational and Psychological Tests for Cross-Cultural Assessment. Mahwah, NJ: Erlbaum.

Harriott, J., and Ferrari, J. R. (1996). Prevalence of procrastination among samples of adults. Psychol. Rep. 78, 611-616. doi: 10.2466/pr0.1996.78.2.611

Hicks, R. E., and Storey, J. (2015). Can procrastination be effective? A study of white-collar employees and university students. Int. J. E-Bus. Res. 15, 39-48. doi: 10.18374/IJBR-15-1.4

Hu, L.-T., and Bentler, P. M. (1999). Cutoff criteria for fit indexes in covariance structure analysis: conventional criteria versus new alternatives. Struct. Equ. Model. 6, 1-55. doi: 10.1080/10705519909540118

Kim, H., Kim, H., Lee, W. K., Han, S., Carlbring, P., and Rozental, A. (2020). Assessing procrastination in Korean: a study of the translation and validation of the pure procrastination scale and a reexamination of the irrational procrastination scale in a student and community sample. Cogent Psychol. 7:1809844. doi: 10.1080/23311908.2020.1809844

Klepikova, N. M., and Kormacheva, I. N. (2019). Adaptation of the procrastination scale and the irrational procrastination scale in P. Steel's technique. СИСТЕМНАЯ ПСИХОЛОГИЯ И СОЦИОЛОГИЯ 3:31. doi: 10.25688/2223-6872.2019.31.3.03

Kline, R. B. (2016). Principles and Practice of Structural Equation Modeling. New York, NY: Guilford.

Klingsieck, K. B. (2013). Procrastination: when good things don't come to those who wait. Eur. Psychol. 18, 24-34. doi: 10.1027/1016-9040/a000138

Krosnick, J. A. (1999). Survey research. Annu. Rev. Psychol. 50, 537-567. doi: 10.1146/annurev.psych.50.1.537
Millsap, R. E., and Olivera-Aguilar, M. (2012). "Investigating measurement invariance using confirmatory factor analysis," in Handbook of Structural Equation Modeling. ed. R. H. Hoyle (New York, NY: Guilford), 380-392.

Nunnally, J. C., and Bernstein, I. H. (1994). Psychometric Theory 3rd Edn. New York, NY: McGraw-Hill.

Prayitno, G. E., Siaputra, I. B., and Lasmono, H. K. (2013). Validasi alat ukur irrational procrastination scale (IPS) [Validation of the irrational procrastination scale (IPS)]. Calyptra 2, 1-7.

R Core Team (2018). R: A language and environment for statistical computing. R Foundation for Statistical Computing, Vienna, Austria. Available at: https:// www.R-project.org/

Rebetez, M. M. L., Rochat, L., Gay, P., and Van der Linden, M. (2014). Validation of a French version of the pure procrastination scale (PPS). Compr. Psychiatry 55, 1442-1447. doi: 10.1016/j.comppsych.2014.04.024

Rosseel, Y. (2018). lavaan 0.6-2 [Software].

Rozental, A., Forsell, E., Svensson, A., Forsström, D., Andersson, G., and Carlbring, P. (2014). Psychometric evaluation of the Swedish version of the pure procrastination scale, the irrational procrastination scale, and the susceptibility to temptation scale in a clinical population. BMC Psychol. 2:54. doi: 10.1186/s40359-014-0054-z

Schouwenburg, H. C., Lay, C. H., Pychyl, T. A., and Ferrari, J. R. (2004). Counseling the Procrastinator in Academic Settings. Washington DC: American Psychological Association.

Shaw, A., Elizondo, F., and Wadlington, P. L. (2020). Reasoning, fast and slow: how noncognitive factors may alter the ability-speed relationship. Intelligence 83:101490. doi: 10.1016/j.intell.2020.101490

Shaw, A., Kapnek, M., and Morelli, N. A. (2021). Measuring creative selfefficacy: an item response theory analysis of the creative self-efficacy (CSE) scale. Front. Psychol. 12:678033. doi: 10.3389/fpsyg.2021.678033

Shaw, A., Liu, O. L., Gu, L., Kardonova, E., Chirikov, I., Li, G., et al. (2020). Thinking critically about critical thinking: validating the Russian HEIghten ${ }^{\circledR}$ critical thinking assessment. Stud. High. Educ. 45, 1933-1948. doi: 10.1080/03075079.2019.1672640

Shaw, A., and Zhang, J. J. (2021). A rasch analysis of the irrational procrastination scale (IPS). Front. Psychol. 11:615341. doi: 10.3389/fpsyg.2020.615341

Sirois, F. M., and Tosti, N. (2012). Lost in the moment? An investigation of procrastination, mindfulness, and well-being. J. Rat. Emot. Cogn. Behav. Therapy 30, 237-248. doi: 10.1007/s10942-012-0151-y

Steel, P. (2007). The nature of procrastination: a meta-analytic and theoretical review of quintessential self-regulatory failure. Psychol. Bull. 133, 65-94. doi: 10.1037/0033-2909.133.1.65

Steel, P. (2010). Arousal, avoidant and decisional procrastinators: do they exist? Personal. Individ. Differ. 48, 926-934. doi: 10.1016/j.paid.2010.02.025

Steel, P., and Ferrari, J. (2013). Sex, education and procrastination: an epidemiological study of procrastinators' characteristics from a global sample. Eur. J. Personal. 27, 51-58. doi: 10.1002/per.1851

Steiger, J. H. (1990). Structural model evaluation and modification: an interval estimation approach. Multivar. Behav. Res. 25, 173-180. doi: 10.1207/ s15327906mbr2502_4

Stępień, M., and Topolewska, E. (2014). "Style tożsamości w ujęciu Berzonsky’ego a prokrastynacja," in Młoda Psychologia. eds. E. Topolewska, E. Skimina and S. Skrzek, vol. 2 (Warszawa: Wydawnictwo Stowarzyszenia Filomatów), 145-160.

Svartdal, F. (2017). Measuring procrastination: psychometric properties of the Norwegian versions of the irrational procrastination scale (IPS) and the pure procrastination scale (PPS). Scand. J. Educ. Res. 61, 18-30. doi: 10.1080/00313831.2015.1066439

Svartdal, F., Pfuhl, G., Nordby, K., Foschi, G., Klingsieck, K. B., Rozental, A., et al. (2016). On the measurement of procrastination: comparing two scales in six European countries. Front. Psychol. 7:1307. doi: 10.3389/fpsyg.2016.01307

Svartdal, F., and Steel, P. (2017). Irrational delay revisited: examining five procrastination scales in a global sample. Front. Psychol. 8:1927. doi: 10.3389/ fpsyg.2017.01927

Tabachnick, B. G., and Fidell, L. S. (2013). Using Multivariate Statistics. 6th Edn. Boston, MA: Pearson.

Tice, D. M., and Baumeister, R. F. (1997). Longitudinal study of procrastination, performance, stress, and health: the costs and benefits of dawdling. Psychol. Sci. 8, 454-458. doi: 10.1111/j.1467-9280.1997.tb00460.x

Tucker, L. R., and Lewis, C. (1973). A reliability coefficient for maximum likelihood factor analysis. Psychometrika 38, 1-10. doi: 10.1007/BF02291170 
Tuckman, B. (1991). The development and concurrent validity of the procrastination scale. Educ. Psychol. Meas. 51, 473-480. doi: 10.1177/0013164 491512022

Van De Schoot, R., Schmidt, P., De Beuckelaer, A., Lek, K., and Zondervan-Zwijnenburg, M. (2015). Measurement invariance. Front. Psychol. 6:01064. doi: 10.3389/fpsyg.2015.01064

Van Eerde, W. (2003). A meta-analytically derived nomological network of procrastination. Personal. Individ. Differ. 35, 1401-1418. doi: 10.1016/ S0191-8869(02)00358-6

Zhang, H., and Zhang, Z. (2007). Usability of tuckman procrastination scale in Chinese college students. Chinese J. Clin. Psychol. 15, 10-12.

Zheng, L., Goldberg, L. R., Zheng, Y., Zhao, Y., Tang, Y., and Liu, L. (2008). Reliability and concurrent validation of the IPIP big-five factor markers in China: consistencies in factor structure between internet-obtained heterosexual and homosexual samples. Personal. Individ. Differ. 45, 649-654. doi: 10.1016/j. paid.2008.07.009
Conflict of Interest: The authors declare that the research was conducted in the absence of any commercial or financial relationships that could be construed as a potential conflict of interest.

Publisher's Note: All claims expressed in this article are solely those of the authors and do not necessarily represent those of their affiliated organizations, or those of the publisher, the editors and the reviewers. Any product that may be evaluated in this article, or claim that may be made by its manufacturer, is not guaranteed or endorsed by the publisher.

Copyright (C) 2021 Shaw and Zhang. This is an open-access article distributed under the terms of the Creative Commons Attribution License (CC BY). The use, distribution or reproduction in other forums is permitted, provided the original author(s) and the copyright owner(s) are credited and that the original publication in this journal is cited, in accordance with accepted academic practice. No use, distribution or reproduction is permitted which does not comply with these terms. 